\title{
Moth Swarm Algorithm for Solving Combined Economic and Emission Dispatch Problem
}

\author{
Milena Jevtic ${ }^{1}$, Nenad Jovanovic ${ }^{2}$, Jordan Radosavljevic ${ }^{2}$, Dardan Klimenta ${ }^{2}$ \\ ${ }^{I}$ Technical Faculty in Bor, University of Belgrade, \\ Vojske Jugoslavije St. 12, RS-19210 Bor, Serbia \\ ${ }^{2}$ Faculty of Technical Sciences Kosovska Mitrovica, University of Pristina in Kosovska Mitrovica, \\ Kneza Milosa St. 7, RS-38220 Kosovska Mitrovica, Serbia \\ mjevtic@tfbor.bg.ac.rs
}

\begin{abstract}
In this paper, the Moth Swarm Algorithm (MSA) is applied to the Combined Economic and Emission Dispatch (CEED) problem in thermal power plants. The analysis of behavior and the evaluation of performances of the algorithm are carried out on the standard test systems with 3 and 6 generators. The results of the MSA application to these test systems are compared with the results published in recent literature. The present paper shows that the proposed MSA gives an accurate and effective solution of the CEED problem.
\end{abstract}

Index Terms-Combined economic and emission dispatch; moth swarm algorithm; power generation dispatch; power engineering computing.

\section{INTRODUCTION}

Minimization of the fuel cost and toxic gases emission $\left(\mathrm{SO}_{2}, \mathrm{CO}_{2}, \mathrm{NO}_{\mathrm{x}}\right)$ in thermal power plants represents a key task in the planning and operation of a power system. This problem is solved in the framework of the Economic Load Dispatch (ELD) and Economic Emission Dispatch (EED) problems. The ELD and EED problems are defined as the processes in which the optimal distribution of generators' output power is determined to deliver the required energy with minimal fuel cost or with minimal emission under specified constraints for power system operating conditions.

The fuel cost can be specified as a quadratic function without or with a sinusoidal term modelling the turbine valve-point loading effect in thermal power plant. The functions describing the dependence of gas emission on generator output power have complex shapes as well. Reducing operating costs (including the fuel cost) and gas emission are mutually conflicting goals. Namely, the reduction of emission requires an increase in operating costs and vice versa. Therefore, the problem is solved as the CEED problem with the two following objectives: minimization of fuel cost and minimization of emission, simultaneously or separately. In case of the CEED problem with such complex functions of operating costs and emission, the classical deterministic algorithms do not give results because they usually converge to locally optimal solutions.

Manuscript received 26 February, 2017; accepted 23 June, 2017. 3046
In cases of this kind, very often, the population-based algorithms inspired by natural systems can be applied. These algorithms give an approximate but sufficiently accurate solution of the problem. Some of these algorithms were applied to solving the ELD problem only, but most of them were applied to solving the whole CEED problem. The population-based algorithms that were used for solving the ELD problem (which is a special case of the CEED problem) are the following: Krill Herd Algorithm [1], Differential Evolution (DE) [2]-[4], Artificial Bee Colony Algorithm [5], Symbiotic Organisms Search Optimization Algorithm [6], Modified Bacterial Foraging Algorithm (MBFA) [7], Gravitational Search Algorithm [8], Biogeography-Based Optimization [9], Quasi-Oppositional Group Search Optimization [10].

The algorithms that were used for solving the CEED problem are the following: Self-Adaptive Firefly Algorithm [11], Grey Wolf Optimizer [12], Spiral Optimization Algorithm (SOA) [13], Multi-Objective Bacterial Foraging Algorithm [14], Particle Swarm Optimization (PSO) [15][17], hybrid Particle Swarm Optimization and Gravitational Search Algorithm (PSOGSA) [18], [19], Galaxy-Based Search Algorithm [20], Gravitational Search Algorithm [21], [22], Hybrid Multi-Objective Optimization Algorithm [23], $\theta$-Particle Swarm Optimization [24], Opposition-Based Gravitational Search Algorithm [25], Opozition-Based Harmony Search Algorithm [26], Parallel Particle Swarm Optimization Algorithm [27], Tribe-Modified Differential Evolution Algorithm [28], Honey-Bees Mating Optimization Algorithm [29], Clonal Selection Algorithm [30], Artificial Bee Colony Algorithm [31], Flower Pollination Algorithm [32], Biogeography-Based Optimization Algorithm [33], Multi-Objective Hybrid Evolutionary Algorithm [34], DE [35], Multi-Objective Differential Evolution Algorithm [36].

In the case of CEED problem, the minimization of fuel cost and emission was carried out with constraints on the generation capacity (generator output power) and on the power balance of the transmission system.

This paper aims to propose the procedure for solving the CEED problem by means of the Moth Swarm Algorithm (MSA), which represents one of the newest population-based algorithms. The results obtained for the standard test systems with 3 and 6 generators are compared to the recently 
reported results of solving the CEED problem.

\section{Model of THE CEED PROBLEM}

Usually, the function of fuel cost for a generator in a thermal power plant is described by a quadratic function of output power $P_{g}$

$$
F_{g}\left(P_{g}\right)=a_{g}+b_{g} P_{g}+c_{g} P_{g}^{2}
$$

where $g=1,2, \ldots, G, F_{g}(\$ / \mathrm{h})$ is the fuel cost of generator $\mathrm{g}$, $P_{g}(\mathrm{MW})$ is the output power of generator $\mathrm{g}, a_{g}, b_{g}$ and $c_{g}$ are the fuel costs coefficients of generator $\mathrm{g}$. The function $F_{g}\left(P_{g}\right)$ is more complex if one is to take into account the valve-point loading effect in a thermal power plant [13], i.e.

$$
F_{g}\left(P_{g}\right)=a_{g}+b_{g} P_{g}+c_{g} P_{g}^{2}+\left|d_{g} \sin \left(e_{g}\left(P_{g}^{\min }-P_{g}\right)\right)\right|,
$$

where $d_{g}$ and $e_{g}$ are the valve-point coefficients and $P_{g}^{\min }$ is the minimum power of generator $g$.

The emission of a generator in a thermal power plant can be modelled by different functions [3]. According to [21] and [31], these functions are quadratic functions or a sum of quadratic and exponential functions, i.e.

$$
E_{g}\left(P_{g}\right)=\alpha_{g}+\beta_{g} P_{g}+\eta_{g} P_{g}^{2}+\xi_{g} \exp \left(\lambda_{g} P_{g}\right),
$$

where $E_{g}$ (ton/h) is the emission of generator $g, P_{g}(\mathrm{MW})$ is the output power of generator $g$, and $\alpha_{g}, \beta_{g}, \eta_{g}, \xi_{g}$ and $\lambda_{g}$ are the emission coefficients of generator $g$.

The CEED problem is formulated by combining the function (1) or (2) with the function (3) using the weighted sum method. Then, the solution of the CEED problem is obtained by minimizing the following objective function [31]

$$
F E=w \sum_{g \in G} F_{g}\left(P_{g}\right)+(1-w) \gamma \sum_{g \in G} E_{g}\left(P_{g}\right),
$$

under the constraints, where $\gamma$ is the scaling factor, $w$ is the weight factor and $G$ is the total number of generators in the thermal power plant. In (4), the limit of the weight factor $w=$ 1 corresponds only to the minimization of $F_{g}\left(P_{g}\right)$, while $w=$ 0 corresponds only to minimization of $E_{g}\left(P_{g}\right)$. The scaling factor $\gamma$ is introduced in (4) in order to solve the bi-objective CEED problem as a single-objective problem. In accordance with other similar studies, this minimization process uses the constraints on the generation capacity and the power balance of the transmission system. The generator capacity constraint is defined as

$$
P_{g}^{\min } \leq P_{g} \leq P_{g}^{\max }
$$

where $P_{g}^{\min }, P_{g}^{\max }$ and $P_{g}$ are the minimum, maximum and actual powers of the generator $g$, respectively.

The power balance constraint is defined by

$$
\sum_{g \in G} P_{g}-P_{D}-P_{\text {loss }}=0
$$

where $P_{D}$ and $P_{\text {loss }}$ are the total load demand and the power loss in the transmission system, respectively. The power loss $P_{\text {loss }}$ is expressed as a quadratic function of the actual powers of generators. The coefficients of this function $B_{g j}$ are defined by the $B$-loss matrix. Then, the power loss is

$$
P_{\text {loss }}=\sum_{g \in G} \sum_{j \in G} P_{g} B_{g j} P_{j}+\sum_{g \in G} B_{0 g} P_{g}+B_{00},
$$

where $B_{g j}, B_{0 g}$ and $B_{00}$ are the coefficients of the associated $B$-loss matrices.

During the optimization process, in order to satisfy the constraint (6), one of the generators $g$ is selected to be a dependent generator (i.e. the slack generator). For this generator (e.g. generator $G$ ), the value of output power $P_{G}$ is calculated from the following equation

$$
P_{G}=P_{D}+P_{\text {loss }}-\sum_{g=1}^{G-1} P_{g}
$$

The power loss $P_{\text {loss }}$ is obtained by: (i) specifying the initial value $P_{\text {loss }}=P_{\text {loss }}^{(0)}=0$ in (8), (ii) expressing the value $P_{G}^{(0)}$ of output power $P_{G}$ from (8) for $P_{\text {loss }}=P_{\text {loss }}^{(0)}=0$, (iii) calculating a new value $P_{\text {loss }}^{(1)}$ of the power loss $P_{\text {loss }}$ using (7), (iv) checking whether the error is below specified error tolerance value $\delta$, i.e.

$$
\left|P_{\text {loss }}^{(1)}-P_{\text {loss }}^{(0)}\right| \leq \delta
$$

and (v) expressing the value $P_{G}^{(1)}$ of output power $P_{G}$ from (8) for $P_{\text {loss }}=P_{\text {loss }}^{(1)}$. If the condition (9) is satisfied, the power balance constraint (6) is met. However, if this is not the case, the procedure is repeated.

When the value of $P_{G}$ is calculated, it is necessary to check whether the value of $P_{G}$ satisfies the constraint (5). Then, the variable $P_{G}^{\lim }$ is defined as

$$
P_{G}^{\lim }=\left\{\begin{array}{ccc}
P_{G}^{\max }, & \text { if } & P_{G}>P_{G}^{\max }, \\
P_{G}^{\min }, & \text { if } & P_{G}<P_{G}^{\min }, \\
P_{G}, & \text { if } & P_{G}^{\min } \leq P_{G} \leq P_{G}^{\max } .
\end{array}\right.
$$

In (8) and (10), the variable $P_{G}$ represents the dependent variable. Thereafter, a quadratic penalty term with the penalty factor $\lambda_{p}$ is added to the objective function $F E$, giving the following extended objective function

$$
F E_{p}=F E+\lambda_{p}\left(P_{G}-P_{G}^{\lim }\right)^{2}
$$

to be minimized. 


\section{SUMMARY OF THE MSA}

The MSA is developed in 2017 [37] and represents one of the newest population-based algorithms. This paper gives the fundamental principle for understanding the application of the MSA. The MSA was developed based on simulation of moth swarms flying toward the moonlight.

In order to be on a straight-line trajectory, during the night, a swarm of moths uses celestial navigation, i.e. a technique in which the direction of flying lies at a constant angle to the parallel light rays of the moon as a remote light source. In applying this technique, the moths encounter the nearby light sources representing obstructions for them. The position of the moth swarm relative to the moon is taken as an optimal solution of the problem, while the quality of the solution is measured on the basis of the intensity of the moth's luminescence.

Each swarm consists of the three following groups of moths [37]: (i) pathfinders that have ability to select the best position as light sources to guide the swarm, i.e. light its path; (ii) prospectors that tend to wander into a spiral path nearby the light sources, which have been marked by the pathfinders; and (iii) onlookers that drift directly towards the moonlight, which represents the best global solution obtained by the prospectors.

One moth in a group is labelled with $m_{j}$, while its luminescence intensity is defined by $f\left(m_{j}\right)$. In each iteration, the whole group of moths is divided into the three groups. The first group consists of pathfinders that have the highest luminescence intensity (they have the best position in the swarm). The second and third best fitnesses in the swarm, as well as the associated groups, are considered as the positions of the prospectors and onlookers, respectively. The MSA consists of the following phases:

1. Phase of initialization. The initial positions of moths are defined as follows

$$
m_{j k}=\operatorname{rand}[0,1] \times\left(\mathrm{m}_{k}^{\max }-m_{k}^{\min }\right)+m_{k}^{\min },
$$

where $\forall j \in\{1,2, \ldots, q\}, k \in\{1,2, \ldots, d\}, d$ is the dimension of the problem, $q$ is the population number, $m_{k}{ }^{\min }$ is the lower limit and $m_{k}^{\max }$ is the upper limit. After initialization, the fitnesses of all the moths are calculated. In addition to this, the moths are classified into the groups based on the calculated fitnesses.

2. Phase of reconnaissance. The precocious convergence (i.e. a stagnation situation) may occur during the optimization process. Pathfinders have the task to prevent this phenomenon by updating its position in interaction with other moths (using lévy-mutation). Lévy-mutation is carried out in accordance with the procedure explained in [37], where the relative dispersion $\sigma_{k}{ }^{i}$ of the pathfinders in the $k^{\text {th }}$ dimension and the variation coefficient $\mu^{i}$ as a limit of relative dispersion need to be first calculated.

Pathfinders that have a low degree of dispersion are inserted in the group $c_{p}$ of crossover points

$$
k \in c_{p} \text { if } \sigma_{k}^{i} \leq \mu^{i}
$$

For crossover points $q_{c} \in c_{p}$, the following vectors are formed: $\quad$ sub-trail vector $\overrightarrow{a_{p}}=\left[a_{p 1}, \mathrm{a}_{p 2}, \ldots, \mathrm{a}_{p q_{c}}\right]$, host vector $\overrightarrow{m_{p}}=\left[m_{p 1}, \mathrm{~m}_{p 2}, \ldots, \mathrm{m}_{p q_{c}}\right]$ and related components of donor vectors, e.g $\overrightarrow{m_{r}^{1}}=\left[m_{r_{1}^{1}}, \mathrm{~m}_{r^{1} 2}, \ldots, \mathrm{m}_{r^{1} q_{c}}\right][38]$.

The sub-trail vector is expressed, using Lévy-mutation [37], as

$$
\overrightarrow{a_{p}^{i}}=\overrightarrow{a_{r^{i}}^{i}}+L_{p 1}^{i} \times\left(\overrightarrow{m_{r^{2}}^{i}},-\overrightarrow{m_{r^{3}}^{i}}\right)+L_{p 2}^{i} \times\left(\overrightarrow{m_{r^{4}}^{i}},-\overrightarrow{m_{r^{5}}^{i}}\right),
$$

where $\forall r^{1} \neq r^{2} \neq r^{3} \neq r^{4} \neq r^{5} \neq p \in\left\{1,2, \ldots, \mathrm{q}_{p}\right\} \overrightarrow{m_{r^{i}}^{i}} . \quad L_{p I}$ and $L_{p 2}$ are the variables generated by a heavy tail Lévyflights [37], [38] using the expression

$$
L_{p} \sim \operatorname{random}\left(q_{c}\right) \oplus \operatorname{Levy}(\alpha),
$$

where $\oplus$ is the entrywise multiplications; Levy $(\alpha)$ is the Lévy flight-random walk, in which the step sizes probability distribution is heavy-tailed [38], [39]; $\alpha$ is the stability index of Lévy $\alpha$-stable distribution. The mutually indexes $\left(r^{1}, r^{2}, r^{3}\right.$, $\left.r^{4}, r^{5}, p\right)$ are selected from the pathfinder solutions.

The crossover operation is carried out so that the trail solution $V_{p k}^{i}$ is

$$
V_{p k}^{i}=\left\{\begin{array}{l}
a_{p k}^{i} \text { if } k \in c_{p} \\
m_{p k}^{i} \text { if } k \notin c_{p}
\end{array},\right.
$$

The selections are carried out according to the following: The fitness values of trail solution and host solution are compared and a better solution is selected to survive for the next generation, as follows

$$
\overrightarrow{m_{p}^{i+1}}=\left\{\begin{array}{l}
\overrightarrow{m_{p}^{i}} \text { if } f\left(\overrightarrow{V_{p}^{i}}\right) \geq f\left(\overrightarrow{m_{p}^{i}}\right), \\
\overrightarrow{a_{p}^{i}} \text { if } f\left(\overrightarrow{V_{p}^{i}}\right)<f\left(\overrightarrow{m_{p}^{i}}\right) .
\end{array}\right.
$$

The probability value of solutions is estimated as

$$
P_{p}=\frac{f i t_{p}}{\sum_{p=1}^{q_{p}} f i t_{p}}
$$

where $f_{i t}$ is the luminescence intensity, which is calculated from the objective function $f_{p}$ for the minimization problems as

$$
\text { fit }_{p}=\left\{\begin{array}{l}
\frac{1}{1+f_{p}}, \text { for } f_{p} \geq 0, \\
1+\left|f_{p}\right|, \text { for } f_{p}<0 .
\end{array}\right.
$$


the lower best luminescence are called the prospectors and their number $q_{f}$ is

$$
q_{f}=\operatorname{round}\left(\left(q-q_{p}\right) \times\left(1-\frac{i}{I}\right)\right) .
$$

The position of each prospector $m_{j}$ is updated according to the mathematical expression for the spiral flight path

$$
m_{j}^{i+1}=\left|m_{j}^{i}-m_{p}^{i}\right| \times e^{\theta} \times \cos 2 \pi \theta+m_{p}^{i},
$$

where $\forall p \in\left\{1,2, \ldots ., q_{p}\right\} ; j \in\left\{q_{p}+1, q_{p}+2, \ldots, q_{f}\right\}, \quad m_{p}$ is chosen on the basis of the probability function $P_{p}(18) ; \theta \in$ $[r, 1]$ is a random number and $r=-1-i / I$. The fact that the new solution for each prospector is better than current pathfinder solutions comes from (21).

4. Onlookers movement. The onlooker moths have the lowest luminescence and they fly to the moonlight. The applied search technique for onlooker solutions is more effectively than the previously illustrated search technique for prospector solutions. The number of onlookers is $q_{0}=q$ $q_{f}-q_{p}$. They are classified in the two following groups: (i) onlookers that move according to Gaussian distribution of steps (their number is $q_{G}=$ round $\left(q_{0} / 2\right)$ ); and (ii) the remaining onlooker moths, with number $q_{A}=q_{0}-q_{G}$, that move according to the Associative Learning Mechanism (ALIM) with short-term memory [37]. The updating equation for the first group of onlookers is created in accordance with the Gaussian walk of random steps

$$
m_{j}^{i+1}=m_{j}^{i}+\varepsilon_{1}+\left[\varepsilon_{2} \times b e s t_{g}^{i}-\varepsilon_{3} \times m_{j}^{i}\right]
$$

where $\forall j \in\left\{1,2, \ldots, \mathrm{q}_{G}\right\}, \forall j \in\left\{1,2, \ldots, \mathrm{q}_{G}\right\}, \quad \varepsilon_{1}$ is a random sample drawn from Gaussian (Normal) distribution as a random sample; size(d) is the size of the first moth group; best $_{g}$ is the global best solution obtained in the phase of moths spiral motion; $\varepsilon_{2}$ and $\varepsilon_{3}$ are uniformly distributed random numbers within the interval $[0,1]$. The updating equation for the second group of onlookers is written on the basis of the ALIM with short-term memory, i.e.

$$
\begin{gathered}
m_{j}^{i+1}=m_{j}^{i}+0.001 \times G\left[m_{j}^{i}-m_{j}^{\min }, m_{j}^{\max }-m_{j}^{i}\right]+ \\
+(1-g / G) \times r_{1} \times \\
\times\left(\text { best }_{p}^{i}-m_{j}^{i}\right)+2 g / G \times r_{2} \times\left(\text { best }_{g}^{i}-m_{j}^{i}\right),
\end{gathered}
$$

where $\forall j \in\left\{1,2, \ldots, q_{A}\right\} \quad 1-g / G$ and $2 g / G$ are the cognitive and social factors, respectively; $r_{1}$ and $r_{2}$ are random numbers within the interval $[0,1]$; best $_{p}$ is the pathfinder solution randomly chosen on the basis of its probability value.

At the end of each iteration, the fitnesses of the whole swarm become available to redefine the role of each moth for the upcoming iteration. Fig. 1 shows the flowchart of the MSA.

\section{Simulation Results}

The proposed MSA algorithm is tested on two test systems, one with 6 generators and another with 3. These test systems are often used for solving the CEED problems by different optimization algorithms. For reasons of comparison, along with the MSA, the authors apply the Firefly Algorithm (FFA) [40] and the PSOGSA [41]. Moreover, the simulated results are compared to the existing results. The MSA, FFA and PSOGSA algorithms have been implemented in MATLAB 2011b computational environment and run on $2.20 \mathrm{GHz}$, with $3.0 \mathrm{~GB}$ RAM. The parameters used for the simulations are presented in the Table I. The best results of the simulations are obtained after 30 runs. The standard IEEE 30-bus six generator system with total load demand of $283.4 \mathrm{MW}$, with $\mathrm{NO}_{\mathrm{x}}$ emission and without the valve point effect is taken as the test system.

TABLE I. THE PARAMETERS OF THE ALGORITHMS APPLIED TO THE TEST SYSTEMS 1 AND 2.

\begin{tabular}{|l|c|c|c|c|c|c|c|c|c|c|c|c|c|c|}
\hline & \multicolumn{1}{|c|}{ MSA } & \multicolumn{10}{c|}{ FFA } & \multicolumn{7}{|c|}{ PSOGSA } \\
\cline { 2 - 16 } & $\mathrm{N}$ & $\mathrm{T}$ & $\mathrm{N}_{\mathrm{c}}$ & $\mathrm{N}$ & $\mathrm{T}$ & $\alpha$ & $\beta_{\min }$ & $\gamma$ & $\mathrm{N}$ & $\mathrm{T}$ & $\mathrm{G}_{0}$ & $\alpha$ & $\mathrm{C}_{1}$ & $\mathrm{C}_{2}$ \\
\hline $\mathbf{1}$ & 50 & 200 & 6 & 50 & 200 & 0.25 & 0.2 & 1 & 50 & 200 & 1 & 10 & 2 & 2 \\
\hline $\mathbf{2}$ & 50 & 200 & 6 & 50 & 200 & 0.25 & 0.2 & 1 & 30 & 50 & 100 & 10 & 2 & 2 \\
\hline
\end{tabular}

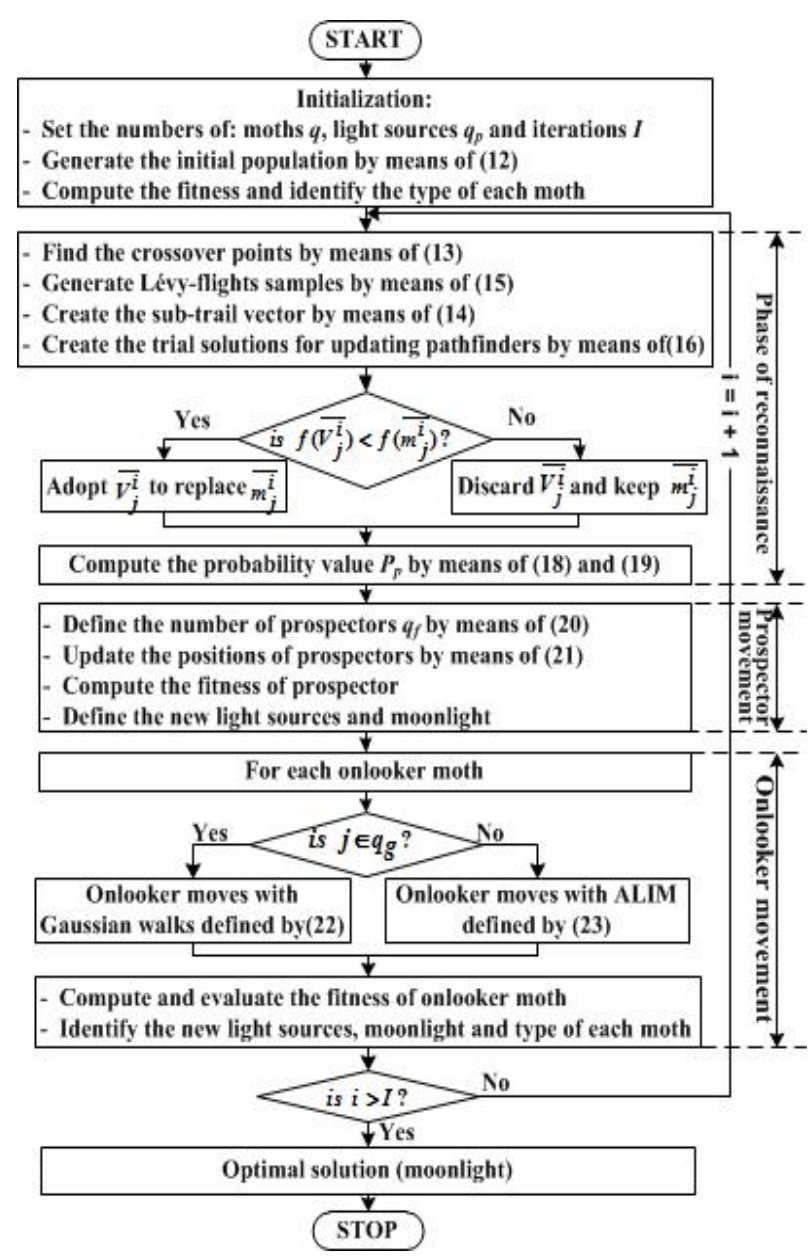

Fig. 1. Flowchart of the MSA.

In order to compare the obtained results to the existing ones, two cases of the test system 1 are considered, one without $P_{\text {loss }}$ (Case I) and another with $P_{\text {loss }}$ (Case II). The error tolerance is $\delta=10^{-6} \mathrm{MW}$. The $B$-loss matrices are given in the Table A-I. The fuel cost coefficients and $\mathrm{NO}_{x}$ emission coefficients appearing in (2)-(4) are taken from [31]. A scaling factor $\gamma_{\mathrm{NOx}}$ of 1000 (\$/ton) is applied. Table II shows the best solutions for the power output, fuel 
cost and emission of the test system 1. Minimization is carried out for the cases: $w=1$ (fuel cost minimization), $w=$ 0 (emission minimization) and $\mathrm{w}=0.5$ (minimization of fuel cost and emission, simultaneously).

TABLE II. THE BEST SOLUTIONS OBTAINED BY MEANS OF THE MSA FOR THE TEST SYSTEM 1.

\begin{tabular}{|c|c|c|c|c|c|c|}
\hline \multirow{2}{*}{ Generation } & \multicolumn{3}{|c|}{ Case I } & \multicolumn{3}{c|}{ Case II } \\
\cline { 2 - 7 } & $\boldsymbol{w}=\mathbf{1}$ & $\boldsymbol{w}=\mathbf{0}$ & $\boldsymbol{w}=\mathbf{0 . 5}$ & $\boldsymbol{w}=\mathbf{1}$ & $\boldsymbol{w}=\mathbf{0}$ & $\boldsymbol{w}=\mathbf{0 . 5}$ \\
\hline$P_{1}(\mathrm{MW})$ & 10.97171 & 40.60695 & 23.23182 & 12.09514 & 41.09296 & 22.55436 \\
\hline$P_{2}(\mathrm{MW})$ & 29.97533 & 45.90863 & 36.03847 & 28.62855 & 46.36389 & 35.45494 \\
\hline$P_{3}(\mathrm{MW})$ & 52.42618 & 53.79580 & 53.88271 & 58.35710 & 54.43888 & 57.00613 \\
\hline$P_{4}(\mathrm{MW})$ & 101.62733 & 38.29380 & 74.57153 & 99.28234 & 39.04004 & 74.54195 \\
\hline$P_{5}(\mathrm{MW})$ & 52.42481 & 53.78922 & 53.88031 & 52.40076 & 54.44660 & 54.81962 \\
\hline$P_{6}(\mathrm{MW})$ & 35.97464 & 51.00560 & 41.79515 & 35.19223 & 51.55068 & 41.55569 \\
\hline $\begin{array}{c}\text { Fuel cost } \\
(\$ / \mathrm{h})\end{array}$ & 600.11141 & 638.27583 & 606.80105 & 605.99837 & 646.20486 & 612.25190 \\
\hline $\begin{array}{l}\text { NO } \mathrm{x} \text { emiss } \\
\text { ion (ton/h) }\end{array}$ & 0.22215 & 0.19420 & 0.20329 & 0.220728 & 0.194179 & 0.203571 \\
\hline$P_{\text {loss }(\mathrm{MW})}$ & - & - & - & 2.55612 & 3.53304 & 2.53268 \\
\hline
\end{tabular}

The test system 2 consists of 3 generators with a load demand of $850 \mathrm{MW}$, as well as with $\mathrm{NO}_{\mathrm{x}}$ and $\mathrm{SO}_{\mathrm{x}}$ emissions. For this system the fuel cost coefficients and $\mathrm{NO}_{\mathrm{x}}$ and $\mathrm{SO}_{\mathrm{x}}$ emission coefficients are taken from [13]. In this case, the scaling factors appearing in (4) are taken from [3] and they are as follows: $\gamma_{\mathrm{NOx}}=147582.78814(\$ /$ ton $)-$ for minimization of the $\mathrm{NO}_{\mathrm{x}}$ emission and $\gamma_{\mathrm{SOx}}=970.031569$ (\$/ton) - for minimization of the $\mathrm{SO}_{\mathrm{x}}$ emission. The test system 2 is considered as a lossless system. Table III shows the minimum, maximum and Standard Deviation values for the cases of applications of the MSA, FFA and PSOGSA to the test system 2. According to Table III, the minimum values of the fuel cost and emission are the same for all the three algorithms. However, the Standard Deviations related to the application of the MSA are by far the lowest of the Standard Deviations obtained for these three applications (i.e. the differences are between 3 and 4 orders of magnitude lower).

In addition, Table IV shows the best solutions for the power output, fuel cost and emission of the test system 2 obtained by means of the MSA for the cases where $w=0, w$ $=1$ and $w=0.5$.
TABLE III. MIN, MAX AND SD VALUES OF THE RESULTS OBTAINED BY MEANS OF THE MSA, FFA AND PSOGSA FOR THE TEST SYSTEM 2

\begin{tabular}{|c|c|c|c|c|}
\hline \multicolumn{2}{|c|}{ Algorithm } & MSA & FFA & PSOGSA \\
\hline \multirow{3}{*}{$\begin{array}{c}\text { Minimization of } \\
\text { fuel cost }\end{array}$} & Min & 8194.35612 & 8194.35612 & 8194.35612 \\
\cline { 2 - 5 } & Max & 8194.35612 & 8194.35612 & 8194.35612 \\
\cline { 2 - 5 } & Std.dev & $4.00 \mathrm{e}-12$ & $1.37 \mathrm{e}-9$ & $2.38 \mathrm{e}-8$ \\
\hline \multirow{3}{*}{$\begin{array}{c}\text { Minimization of } \\
\text { NOx emission }\end{array}$} & Min & 0.096738 & 0.097338 & 0.095138 \\
\cline { 2 - 5 } & Max & 0.096738 & 0.096738 & 0.095138 \\
\cline { 2 - 5 } & Std.dev & $1.14 \mathrm{e}-15$ & $1.80 \mathrm{e}-12$ & $2.93 \mathrm{e}-12$ \\
\hline \multirow{2}{*}{$\begin{array}{c}\text { Minimization of } \\
\mathrm{SO}_{\mathrm{x}} \text { emission }\end{array}$} & Min & 8.820849 & 8.820849 & 8.820849 \\
\cline { 2 - 5 } & Max & 8.820849 & 8.820849 & 8.820849 \\
\cline { 2 - 5 } & Std.dev & $8.73 \mathrm{e}-16$ & $1.13 \mathrm{e}-12$ & $1.80 \mathrm{e}-11$ \\
\hline
\end{tabular}

TABLE IV. THE BEST SOLUTIONS OBTAINED BY MEANS OF THE MSA FOR THE TEST SYSTEM 2.

\begin{tabular}{|c|c|c|c|c|}
\hline & \begin{tabular}{|c|}
$\begin{array}{c}\text { Minimization } \\
\text { of fuel cost }\end{array}$ \\
$(w=1)$
\end{tabular} & $\begin{array}{c}\text { Minimization } \\
\text { of } \\
\text { NO }_{\mathrm{x}} \mathrm{emission} \\
(w=0)\end{array}$ & $\begin{array}{c}\text { Minimization } \\
\text { of SO } \\
\text { emission } \\
(w=0)\end{array}$ & $\begin{array}{c}\text { Minimization } \\
\text { of fuel cost and } \\
\text { emission ( } w= \\
0.5)\end{array}$ \\
\hline$P_{l}(\mathrm{MW})$ & 393.16983 & 542.61947 & 542.61947 & 495.33897 \\
\hline $\begin{array}{c}P_{2} \\
(\mathrm{MW})\end{array}$ & 334.60376 & 227.39222 & 227.39221 & 249.88672 \\
\hline$P_{3}(\mathrm{MW})$ & 122.22641 & 79.98831 & 79.98832 & 104.77431 \\
\hline $\begin{array}{c}\text { Fuel } \\
\text { cost } \\
(\$ / \mathrm{h})\end{array}$ & 8194.35612 & 8260.14181 & 8260.14182 & 8226.05250 \\
\hline $\begin{array}{c}\mathrm{NO}_{\mathrm{x}} \\
\text { emission }\end{array}$ & 0.099677 & 0.096738 & 0.096738 & 0.095143 \\
\hline $\begin{array}{c}\mathrm{SO}_{\mathrm{x}} \\
\text { emission }\end{array}$ & 8.891854 & 8.820849 & 8.820849 & 8.828920 \\
\hline
\end{tabular}

The results obtained by the MSA and FFA for the test system 1 along with corresponding data from the literature are summarized in the Table $\mathrm{V}$.

As can be seen in Table V, the MSA and FFA provided better values for the minimum fuel cost in regard to the values obtained by the algorithms proposed in [7], [13], [15], [17] and [23], as well as ones that are the same or very close to the results obtained by the algorithms from [18] and [35]. The minimum value of $\mathrm{NO}_{\mathrm{x}}$ emission calculated by the MSA and FFA are the same or better than the associated results reported in [7], [15], [17], [18], [23] and [35].

TABLE V. A COMPARISON OF THE BEST SOLUTIONS FOR THE FUEL COST AND NOX EMISSION OF THE TEST SYSTEM 1.

\begin{tabular}{|c|c|c|c|c|c|c|c|c|c|c|c|c|}
\hline \multirow[t]{3}{*}{ Algorithms } & \multicolumn{6}{|c|}{ Case I } & \multicolumn{6}{|c|}{ Case II } \\
\hline & \multicolumn{2}{|c|}{$\begin{array}{c}\text { Minimization of fuel } \\
\text { cost } \\
(w=1)\end{array}$} & \multicolumn{2}{|c|}{$\begin{array}{c}\text { Minimization of } \mathrm{NO}_{\mathrm{x}} \\
\text { emission } \\
(w=0)\end{array}$} & \multicolumn{2}{|c|}{$\begin{array}{c}\text { Minimization of fuel } \\
\text { cost and } \mathrm{NO}_{\mathrm{x}} \text { emission } \\
(w=0.5)\end{array}$} & \multicolumn{2}{|c|}{$\begin{array}{c}\text { Minimization of fuel } \\
\text { cost } \\
(w=1)\end{array}$} & \multicolumn{2}{|c|}{$\begin{array}{c}\text { Minimization of } \\
\text { NO } \mathrm{x}_{\mathrm{x}} \text { emission } \\
\quad(w=0)\end{array}$} & \multicolumn{2}{|c|}{$\begin{array}{c}\text { Minimization of fuel } \\
\text { cost and } \mathrm{NO}_{\mathrm{x}} \\
\text { emission }(w=0.5)\end{array}$} \\
\hline & $\begin{array}{c}\text { Fuel cost } \\
(\$ / h)\end{array}$ & \begin{tabular}{|c|} 
Emission \\
(ton $/ \mathrm{h}$ )
\end{tabular} & $\begin{array}{c}\text { Fuel cost } \\
(\$ / h)\end{array}$ & $\begin{array}{c}\text { Emission } \\
\text { (ton/h) }\end{array}$ & $\begin{array}{c}\text { Fuel cost } \\
(\$ / h)\end{array}$ & $\begin{array}{c}\text { Emission } \\
\text { (ton } / \mathrm{h} \text { ) }\end{array}$ & $\begin{array}{c}\text { Fuel cost } \\
(\$ / \mathrm{h})\end{array}$ & $\begin{array}{c}\text { Emission } \\
\text { (ton/h) }\end{array}$ & $\begin{array}{c}\text { Fuel cost } \\
(\$ / h)\end{array}$ & $\begin{array}{c}\text { Emission } \\
\text { (ton/h) }\end{array}$ & $\begin{array}{c}\text { Fuel cost } \\
(\$ / h)\end{array}$ & \begin{tabular}{|c} 
Emission \\
(ton/h)
\end{tabular} \\
\hline MSA & 600.11141 & 0.22215 & 638.27583 & 0.194203 & 606.80105 & 0.20329 & 605.99837 & 0.220728 & 646.20486 & 0.194179 & 612.25190 & 0.203571 \\
\hline FFA & 600.11141 & 0.22214 & 638.27398 & 0.194203 & 606.79835 & 0.20329 & 605.99837 & 0.220728 & 646.20731 & 0.194179 & 612.25302 & 0.203570 \\
\hline PSOGSA[18] & 600.11141 & 0.22215 & 638.27452 & 0.194203 & 606.79841 & 0.20329 & 605.99837 & 0.220728 & 646.20838 & 0.194179 & 612.25222 & 0.203571 \\
\hline MBFA [7] & 600.17 & & 636.73 & & 610.906 & 0.2000 & 607.6700 & 0.2198 & 644.4300 & 0.1942 & 616.496 & 0.2002 \\
\hline SOA [13] & 600.986 & 0.20889 & 640.749 & 0.18729 & 624.604 & 0.18708 & - & - & - & - & - & - \\
\hline $\mathrm{PSO}[15]$ & 600.13 & 0.2199 & 636.62 & 0.1943 & - & - & 607.8400 & 0.2192 & 642.9000 & 0.1942 & - & - \\
\hline MOPSO [17] & 600.12 & 0.2216 & 637.42 & 0.1942 & 608.65 & 0.2017 & 607.7900 & 0.2193 & 644.7400 & 0.1942 & 615.000 & 0.2021 \\
\hline $\mathrm{DE}[35]$ & 600.1114 & 0.2221 & 638.2907 & 0.1942 & - & - & 608.0658 & 0.2193 & 645.0850 & 0.1942 & - & - \\
\hline $\begin{array}{c}\text { MODE/PSO } \\
{[23]}\end{array}$ & 600.115 & 0.22201 & 638.270 & 0.194203 & - & - & 606.0073 & 0.2209 & 646.0243 & 0.1942 & - & - \\
\hline
\end{tabular}


The Table $\mathrm{V}$ also reveals that the effect of the power loss $P_{\text {loss }}$ on the valus of the minimum fuel cost and emission is very small or negligible. Figure 2 shows the convergence behaviors of the MSA, FFA and PSOGSA in the cases of minimization of fuel cost and minimization of emission for the test systems 1 and 2 .

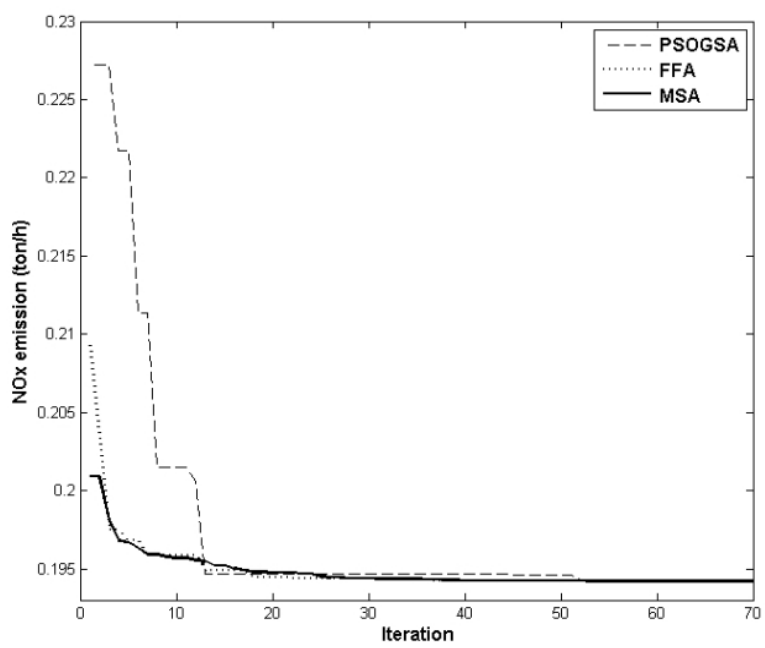

(a)

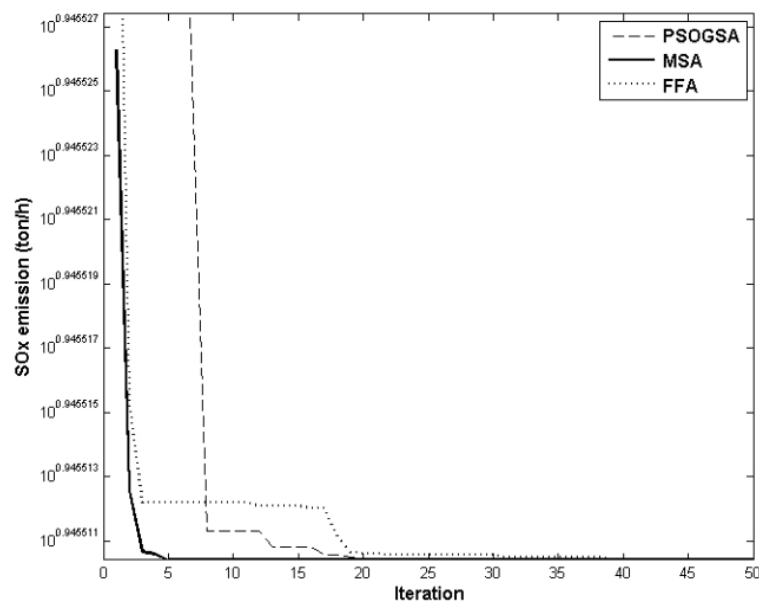

(b)

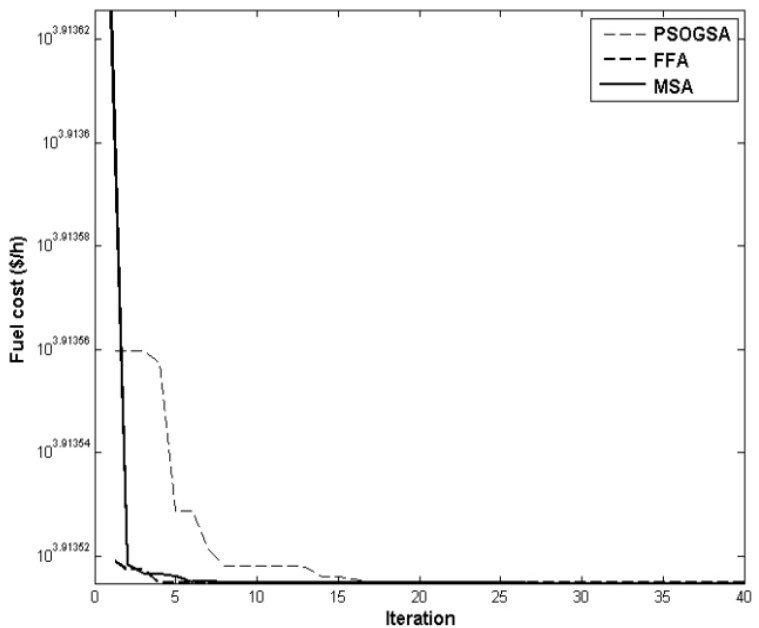

(c)

Fig. 2. Comparative convergence curves of the MSA, PSOGSA and FFA: (a) in the case of minimization of $\mathrm{NO}_{\mathrm{x}}$ emission for the test system 1 without $P_{\text {loss }}$; (b) in the case of minimization of $\mathrm{SO}_{\mathrm{x}}$ emission for the test system 2; and (c) in the case of minimization of fuel cost for the test system 2 .
According to Fig. 2, the MSA converges to the minimum value in a number of iterations which is lower than the one for the PSOGSA. Compared to the FFA, the MSA converges in a number of iterations which is lower (Fig. 2(b)) or approximately the same (Fig. 1(a) and Fig. 1(c)). For all three algorithms, ascend speeds are high at the beginning.

\section{CONCLUSIONS}

The application of the MSA to the CEED problem has been proposed in this paper for the first time. The algorithm has been successfully tested on the two standard IEEE test systems with 3 and 6 generators. The comparative analysis of the results obtained by means of the MSA, FFA and PSOGSA showed that the Standard Deviations of the results are the lowest for the MSA (between $4 \cdot 10^{-12}$ - for minimization of the fuel cost and $8.73 \cdot 10^{-16}$ - for minimization of the $\mathrm{SO}_{\mathrm{x}}$ emission), indicating a larger degree of robustness for the MSA.

Moreover, the MSA generated the minimal values of the fuel cost and $\mathrm{NO}_{\mathrm{x}}$ emission that are the same as to the corresponding results of the FFA and PSOGSA. In addition, these minimal values are better than the associated ones that are obtained using the recently developed algorithms, thus resulting in the high quality solution. The convergence profiles of the objective functions used in the MSA, FFA and PSOGSA showed that the ascend speeds are high at the beginning for all three algorithms. Compared to the FFA and PSOGSA, the MSA can achieve the optimal solution much faster. Thus, the MSA was demonstrated to have a better convergence property. Finaly, comparisons between the convergence profiles, Standard Deviations and optimal values of the results presented in this paper and in the existing literature also showed the best effectiveness and robustness of the MSA for solving CEED problem.

The MSA is also suitable for solving other complex and non-smooth problems, of course, having in mind the "No Free Lunch" theorem [37] which states that it is not usually possible to find a single algorithm that can solve all optimization problems. Therefore, the MSA, which is currently one of the newest population-based optimization algorithms, should be tested and applied to other scientific and engineering problems.

\section{APPENDIX A}

TABLE A-I. THE $B$-LOSS MATRICES FOR THE TEST SYSTEM 1.

\begin{tabular}{|c|cccccc|}
\hline $\begin{array}{c}\text { Matri } \\
\text { ces }\end{array}$ & \multicolumn{7}{|c|}{ Matrix elements } \\
\hline \multirow{3}{*}{$\mathrm{B}$} & {$\left[\begin{array}{ccccccc}0.1382 & -0.0299 & 0.0044 & -0.0022 & -0.0010 & -0.0008 \\
-0.0299 & 0.0487 & -0.0025 & 0.0004 & 0.0016 & 0.0041 \\
& 0.0044 & -0.0025 & 0.0182 & -0.0070 & -0.0066 & -0.0066 \\
& -0.0022 & 0.0004 & -0.0070 & 0.0137 & 0.0050 & 0.0033 \\
& -0.0010 & 0.0016 & -0.0066 & 0.0050 & 0.0109 & 0.0005 \\
-0.0008 & 0.0041 & -0.0066 & 0.0033 & 0.0005 & 0.0244\end{array}\right]$} \\
\hline $\mathrm{B}_{0}$ & {$\left[\begin{array}{llllll}-0.0107 & 0.0060 & -0.0017 & 0.0009 & 0.0002 & 0.0030\end{array}\right]$} \\
\hline $\mathrm{B}_{00}$ & \multicolumn{7}{|c}{$[0.00098573]$} \\
\hline
\end{tabular}


TABLE A-II. THE FUEL COST COEFFICIENTS, NOx EMISSION COEFFICIENTS AND GENERATION LIMITS FOR THE TEST SYSTEM 1.

\begin{tabular}{|c|c|c|c|c|c|c|c|c|c|c|}
\hline$g$ & $a_{g}$ & $b_{g}$ & $c_{g}$ & $\alpha_{g}$ & $\boldsymbol{\beta}_{g}$ & $\eta_{g}$ & $\xi_{g}$ & $\lambda g$ & $P_{g}^{\min }$ & $P_{g}^{\max }$ \\
\hline 1 & 10 & 200 & 100 & $4.091 \mathrm{e}-2$ & $-5.554 \mathrm{e}-2$ & $6.490 \mathrm{e}-2$ & $2.0 \mathrm{e}-4$ & 2.857 & 5 & 150 \\
\hline 2 & 10 & 150 & 120 & $2.543 \mathrm{e}-2$ & $-6.047 \mathrm{e}-2$ & $5.638 \mathrm{e}-2$ & $5.0 \mathrm{e}-4$ & 3.333 & 5 & 150 \\
\hline 3 & 20 & 180 & 40 & $4.258 \mathrm{e}-2$ & $-5.094 \mathrm{e}-2$ & $4.586 \mathrm{e}-2$ & $1.0 \mathrm{e}-6$ & 8.0 & 5 & 150 \\
\hline 4 & 10 & 100 & 60 & $5.326 \mathrm{e}-2$ & $-3.550 \mathrm{e}-2$ & $3.380 \mathrm{e}-2$ & $2.0 \mathrm{e}-3$ & 2.0 & 5 & 150 \\
\hline 5 & 20 & 180 & 40 & $4.258 \mathrm{e}-2$ & $-5.094 \mathrm{e}-2$ & $4.586 \mathrm{e}-2$ & $1.0 \mathrm{e}-6$ & 8.0 & 5 & 150 \\
\hline 6 & 10 & 150 & 100 & $6.131 \mathrm{e}-2$ & $-5.555 e-2$ & $5.151 \mathrm{e}-2$ & $1.0 \mathrm{e}-5$ & 6.667 & 5 & 150 \\
\hline
\end{tabular}

TABLE A-III. THE FUEL COST COEFFICIENTS, NOx AND SOx EMISSION COEFFICIENTS AND GENERATION LIMITS FOR THE TEST SYSTEM 2.

\begin{tabular}{|c|c|c|c|c|c|c|c|c|c|c|c|}
\hline$g$ & $a_{g}$ & $b_{g}$ & $c_{g}$ & $\alpha_{g S O x}$ & $\beta_{g S O x}$ & $\eta_{g S O x}$ & $\alpha_{g N O x}$ & $\boldsymbol{\beta}_{g N O x}$ & $\eta_{g N O x}$ & $P_{g}^{\min }$ & $P_{g}^{\max }$ \\
\hline 1 & 561 & 7.9200 & 0.001562 & 0.5783298 & 0.00816466 & $1.6103 \mathrm{e}-6$ & 0.043732540 & $-9.4868099 e-5$ & $1.4721848 \mathrm{e}-7$ & 150 & 600 \\
\hline 2 & 310 & 7.8500 & 0.001940 & 0.3515338 & 0.00891174 & $2.1999 \mathrm{e}-6$ & 0.055821713 & $-9.7252878 e-5$ & $3.0207577 \mathrm{e}-7$ & 100 & 400 \\
\hline 3 & 78 & 7.9700 & 0.004820 & 0.0884504 & 0.00903782 & $5.4658 \mathrm{e}-6$ & 0.027731524 & $-3.5373734 e-4$ & $1.9338531 \mathrm{e}-6$ & 50 & 200 \\
\hline
\end{tabular}

\section{REFERENCES}

[1] B. Mandal, P. K. Roy, S. Mandal, "Economic load dispatch using krill herd algorithm", Int. Journal of Electrical Power and Energy Systems, vol. 57, pp. 1-10, 2014. [Online]. Available: https://doi.org/10.1016/j.ijepes.2013.11.016

[2] M. H. R. Nascimento, M. V. A. Nunes, J. L. M. Rodriguez, J. C. Leite, "A new solution to the economical load dispatch of power plants and optimization using differential evolution", Electrical Engineering, pp. 1-11, 2016. [Online]. Available: https://doi.org/ 10.1007/s00202-016-0385-2

[3] A. Bhattacharya, P. K. Chattopadhyay, "Solving economic emission load dispatch problems using hybrid differential evolution", Applied Soft Computing, vol. 11, no. 2, pp. 2526-2537, 2011. [Online]. Available: https://doi.org/10.1016/j.asoc. 2010.09.008

[4] A. Dogan, T. Yalcinoz, M. Alci, "A comparison of heuristic methods for optimum power flow considering valve point effect", Elektronika Ir Elektrotechnika, vol. 22, no. 5, pp. 32-37, 2016. [Online]. Available: https://doi.org/10.5755/j01.eie.22.5.16340

[5] A. G. Abro, J. M. Saleh, "Enhanced probability-selection artificial bee colony algorithm for economic load dispatch: A comprehensive analysis", Engineering Optimization, vol. 46, no. 10, pp. 1315-1330, 2014. [Online]. Available: http://dx.doi.org/10.1080/0305215X. 2013.836639

[6] M. K. Dosoglu, U. Guvenc, S. Duman, Y. Sonmez, H. T. Kahraman, "Symbiotic organisms search optimization algorithm for economic/emission dispatch problem in power systems", Neural Computing and Applications, pp. 1-17, 2016. [Online]. Available: http://dx.doi.org/10.1007/s00521-016-2481-7

[7] P. K. Hota, A. K. Barisal, R. Chakrabarti, "Economic emission load dispatch through fuzzy based bacterial foraging algorithm", Int. Journal of Electrical Power and Energy Systems, vol. 32, no. 7, pp. 794-803, 2010. [Online]. Available: https://doi.org/10.1016/j.ijepes. 2010.01.016

[8] R. J. Chinasamy Hemparuva, S. P. Simon, S. Kinattingal, S. R. N. Panugothu, "Gravitational search algorithm-based dynamic economic dispatch by estimating transmission system losses using A-loss coefficients", Turkish Journal of Electrical Engineering and Computer Sciences, vol. 24, no. 5, pp. 3769-3781, 2016. [Online]. Available: https://doi.org/10.3906/elk-1412-152

[9] J. Singh, S. K. Goyal, "Transmission constrained economic load dispatch using biogeography based optimization", IEEE Int. Conf. Computational Intelligence and Computing Research (ICCIC), 2014, pp. 1-5. [Online]. Available: https://doi.org/ 10.1109/ICCIC.2014. 7238511

[10] M. Basu, "Quasi-oppositional group search optimization for multiarea dynamic economic dispatch", Int. Journal of Electrical Power and Energy Systems, vol. 78, pp. 356-367, 2016. [Online]. Available: https://doi.org/10.1016/j.ijepes.2015.11.120

[11] G. Chen, X. Ding, "Optimal economic dispatch with valve loading effect using self-adaptive firefly algorithm", Applied Intelligence, vol. 42, no. 2, pp. 276-288, 2015. [Online]. Available: https://doi.org/10.1007/s10489-014-0593-2
[12] V. K. Kamboj, S. K. Bath, J. S. Dhillon, "Solution of non-convex economic load dispatch problem using Grey Wolf Optimizer", Neural Computing and Applications, vol. 27, no. 5, pp. 1301-1316, 2016. [Online]. Available: https://doi.org/10.1007/s00521-015-1934-8

[13] L. Benasla, A. Belmadani, M. Rahli, "Spiral optimization algorithm for solving combined economic and emission dispatch", Int. Journal of Electrical Power and Energy Systems, vol. 62, pp. 163-174, 2014. [Online]. Available: https://doi.org/10.1016/ j.ijepes.2014.04.037

[14] V. R. Pandi, B. K. Panigrahi, W. C. Hong, R. Sharma, "A multiobjective bacterial foraging algorithm to solve the environmental economic dispatch problem", Energy Sources, Part B: Economics, Planning and Policy, vol. 9, no. 3, pp. 236-247, 2014. [Online]. Available: http://dx.doi.org/10.1080/15567249.2010. 485167

[15] J. Hazra, A. K. Sinha, “A multi-objective power flow using particle swarm optimization", European Trans. on Electrical Power, vol. 21, no. 1, pp. 1028-1045, 2011. [Online]. Available: http://dx.doi.org/ 10.1002/etep.494

[16] N. A. Khan, G. A. S. Sidhu, F. Gao, "Optimizing combined emission economic dispatch for solar integrated power systems", IEEE Access, vol. 4, pp. 3340-3348, 2016. [Online]. Available: http://dx.doi.org/ 10.1109/ACCESS.2016.2587665

[17] M. A. Abido, "Multiobjective particle swarm optimization for environmental/economic dispatch problem", Electric Power Systems Research, vol. 79, no.7, pp. 1105-1113, 2009.

[18] J. Radosavljevic, "A solution to the combined economic and emission dispatch using hybrid PSOGSA algorithm", Applied Artificial Intelligence, vol. 30, no. 5, pp. 445-474, 2016. [Online]. Available: http://dx.doi.org/10.1080/08839514. 2016.1185860

[19] S. Jiang, Z. Ji, Y. Shen, "A novel hybrid particle swarm optimization and gravitational search algorithm for solving economic emission load dispatch problems with various practical constraints", Int. Journal of Electrical Power and Energy Systems, vol. 55, pp. 628644, 2014. [Online]. Available: https://doi.org/10.1016/j.ijepes. 2013.10.006

[20] D. H. Zerigat, L. Benasla, A. Belmadani, "Galaxy-based search algorithm to solve combined economic and emission dispatch", UPB Scientific Bulletin, Series C: Electrical Engineering, vol. 76, no. 1, pp. 209-220, 2014.

[21] U. Guvenc, Y. Sonmez, S. Duman, N. Yorukeren, "Combined economic and emission dispatch solution using Gravitational search algorithm", Scientia Iranica, vol. 19, no. 6, pp. 1754-1762, 2012. [Online]. Available: https://doi.org/10.1016/j.scient. 2012.02.030

[22] J. Radosavljevicc, "Gravitational search algorithm for solving combined economic and emission dispatch", in Proc. XIV Int. Scientific-Professional Symposium Infoteh, Jahorina, Bosnia and Herzegovina, 2015.

[23] D. W. Gong, Y. Zhang, C. L. Qi, "Environmental/economic power dispatch using a hybrid multi-objective optimization algorithm", Int. Journal of Electrical Power and Energy Systems, vol. 32, no. 6, pp. 607-614, 2010. [Online]. Available: https://doi.org/10.1016/j.ijepes. 2009.11.017

[24] T. Niknam, H. Doagou-Mojarrad, "Multiobjective economic/emission dispatch by multiobjective $\theta$-particle swarm 
optimization", IET Generation, Transmission \& Distribution, vol. 6, no. 5, pp. 363-370, 2012. [Online]. Available: https://doi.org/ 10.1049 /iet-gtd.2011.0698

[25] B. Shaw, V. Mukherjee, S. P. Ghoshal, "A novel opposition-based gravitational search algorithm for combined economic and emission dispatch problems of power systems", Int. Journal of Electrical Power and Energy Systems, vol. 35, no. 1, pp. 21-33, 2012. [Online] Available: https://doi.org/10.1016/j.ijepes. 2011.08.012

[26] A. Chatterjee, S. P. Ghoshal, V. Mukherjee, "Solution of combined economic and emission dispatch problems of power systems by an opposition-based harmony search algorithm", Int. Journal of Electrical Power and Energy Systems, vol. 39, no. 1, pp. 9-20, 2012. [Online]. Available: https://doi.org/10.1016/ j.ijepes.2011.12.004

[27] H. Hamedi, "Solving the combined economic load and emission dispatch problems using new heuristic algorithm", Int. Journal of Electrical Power and Energy Systems, vol. 46, pp. 10-16, 2013. [Online]. Available: https://doi.org/10.1016/j.ijepes.2012.09.021

[28] T. Niknam, H. D. Mojarrad, B. B. Firouzi, "A new optimization algorithm for multi-objective economic/emission dispatch", Int. Journal of Electrical Power and Energy Systems, vol. 46, pp. 283 293, 2013. [Online]. Available: https://doi.org/10.1016/ j.ijepes.2012.10.001

[29] A. Ghasemi, "A fuzzified multi objective interactive honey bee mating optimization for environmental/economic power dispatch with valve point effect", Int. Journal of Electrical Power and Energy Systems, vol. 49, no. 308-321, 2013. [Online]. Available: https://doi.org/10.1016/j.ijepes.2013.01.012

[30] B. S. Rao, K. Vaisakh, "Multi-objective adaptive clonal selection algorithm for solving environmental/economic dispatch and OPF problems with load uncertainty", Int. Journal of Electrical Power and Energy Systems, vol. 53, pp. 390-408, 2013. [Online]. Available: https://doi.org/10.1016/j.ijepes.2013.04.024

[31] D. Aydin, S. Ozyon, C. Yasar, T. Liao, "Artificial bee colony algorithm with dynamic population size to combined economic and emission dispatch problem", Int. Journal of Electrical Power and Energy Systems, vol. 54, pp. 144-153, 2014. [Online]. Available: https://doi.org/10.1016/j.ijepes.2013.06.020

[32] A. Y. Abdelaziz, E. S. Ali, S. M. AbdElazim, "Combined economic and emission dispatch solution using flower pollination algorithm", Int. Journal of Electrical Power and Energy Systems, vol. 80, pp.
264-274, 2016. [Online]. Available: https://doi.org/10.1016/j.ijepes. 2015.11.093

[33] P. K. Roy, S. P. Ghoshal, S. S. Thakur, "Combined economic and emission dispatch problems using biogeography-based optimization", Electrical Engineering, vol. 92, no. 4, pp. 173-184, 2010. [Online]. Available: https://doi.org/10.1007/s00202-010-0173-3

[34] P. K. Roy, S. Bhui, "A multi-objective hybrid evolutionary algorithm for dynamic economic emission load dispatch", Int. Trans. Electrical Energy Systems, vol. 26, pp. 49-78, 2016. [Online]. Available: https://doi.org/10.1002/etep.2066

[35] A. A. Abou El Ela, M. A. Abido, S. R. Spea, "Differential evolution algorithm for emission constrained economic power dispatch problem", Electric Power Systems Research, vol. 80, no. 10, pp. 1286-1292, 2010. [Online]. Available: https://doi.org/10.1016/j.epsr 2010.04.011

[36] B. Y. Qu, J. J. Liang, Y. S. Zhu, P. N. Suganthanl, "Solving dynamic economic emission dispatch problem considering wind power by multi-objective differential evolution with ensemble of selection method", Natural Computing, pp. 1-9, 2017. [Online]. Available: https://doi.org/10.1007/s11047-016-9598-6

[37] A. A. Mohamed, Y. S. Mohamed, A. A. M. El-Gaafary, A. M Hemeida, "Optimal power flow using moth swarm algorithm", Electric Power System Research, vol. 142, pp. 190-206, 2017. [Online]. Available: https://doi.org/10.1016/j.epsr.2016.09.025

[38] R. N. Mantegna, "Fast, accurate algorithm for numerical simulation of Levy stable stochastic processes", Physical Review. E, vol. 49, no. 5, pp. 4677-4683, 1994. [Online]. Available: https://doi.org/10.1103/ PhysRevE.49.4677

[39] S. Borak, W. Hardle, R. Weron, Stable distributions Statistical Tools for Finance and Insurance. Heidelberg: Springer Berlin, 2016, pp. 21-44.

[40] X. S. Yang, "Firefly algorithm, L'evy flights and global optimization", in Research and Development in Intelligent Systems XXVI. Springer London, 2010, pp. 209-218. [Online]. Available: https://doi.org/10.1007/978-1-84882-983-1 15

[41] S. Mirjalli, S. Z. M. Hashim, H. M. Sardroudi, "Training feedforward neural networks using hybrid particle swarm and gravitational search algorithm", Applied Mathematics and Computation, vol. 218, pp. 11125-11137, 2012. [Online]. Available: https://doi.org/10.1016/ j.amc.2012.04.069 